\title{
Study on NO selective adsorption performance of Rh/MOF-177
}

\author{
fushun Tang ${ }^{1}$, Ying Zhai ${ }^{1}$, Shengchen $\mathrm{Li}^{1}$, Lei $\mathrm{Li}^{1}$, Xiaxia $\mathrm{Wei}^{1}$, Jie $\mathrm{Hu}^{1}$, Le Ruan ${ }^{1}$, and \\ Zhe Zhang $^{1}$ \\ ${ }^{1}$ Affiliation not available
}

October 31, 2020

\begin{abstract}
In this paper, the NO adsorption performance of Rh/MOF-177 was studied by pulse method. Based on further confirming the literature molecular simulation results which $\mathrm{NO}, \mathrm{O}_{2}$ and $\mathrm{CO}_{2}$ were adsorbed very little and $\mathrm{N}_{2}$ was hardly adsorbed, it was found that the MOF-177 material showed great carrier function, and promoted the atomic-sized high dispersion and stability of almost supported Rh particles on MOF-177. The adsorption properties of NO was greatly improved after Rh was introduced into MOF-177 which the adsorption capacity of Rh/MOF-177 with $3 \%$ Rh loading can reach about $310 \times 10^{-3} \mathrm{mmol}^{2}$ ?] $\mathrm{g}^{-1}$ by pulse method and was about 15-20 times higher than that of $\mathrm{O}_{2}$ and $\mathrm{CO}_{2}$ with near $90 \%$ adsorption selectivity in simulated flue gas atmosphere. The NO adsorption capacity of Rh/MOF-177 was related to the reduced $\mathrm{Rh}^{0}$ which one reduced $\mathrm{Rh}^{0}$ adsorbed three NO molecules, and NO adsorption form on Rh/MOF-177 should be a trinitro-group (Rh(NO) $\left.)_{3}\right)$ species.
\end{abstract}

\section{Study on NO selective adsorption performance of Rh/MOF-177}

Ying Zhai,Shengchen Li,Lei Li, Xiaxia Wei,Jie Hu,Fushun Tang $11^{*}$ Corresponding author:tfushun@163.com;zhangzhe@glut.edu.cn. Financial support: Guangxi Science Research and Technology Development Project of China (Grant No. AA18118010).,Le Ruan, Zhe Zhang*

College of Chemistry and Bioengineering, Guilin University of Technology, Guilin 541004, China

\section{Highlights}

- Almost atomic-sized Rh particles with high dispersion and high stability were firstly prepared by loading method on MOF-177, the Rh/MOF-177 material showed high NO adsorption capacity and adsorption selectivity, and preliminarily exhibited the potential of adsorptive-separating purification and resource utilization of atmospheric pollutant NO in flue gas.

- The experiment verified the literature molecular simulation results of MOF-177 that $\mathrm{NO}, \mathrm{O}_{2}$ and $\mathrm{CO}_{2}$ were adsorbed very little and $\mathrm{N}_{2}$ was hardly adsorbed.

- The structure-function relationship between the chemical and dispersion state of Rh/MOF-177 and NO adsorptive properties was obtained. The NO adsorption capacity of Rh/MOF-177 was related to the reduced $\mathrm{Rh}^{0}$ and increased proportionally with the increase of $\mathrm{Rh}$ loadings. One reduced $\mathrm{Rh}^{0}$ adsorbed three NO molecules and the adsorption form of $\mathrm{NO}$ on $\mathrm{Rh} / \mathrm{MOF}-177$ should be the adsorbed trinitro group species $\mathrm{Rh}(\mathrm{NO})_{3}$.

Abstract: In this paper, the NO adsorption performance of Rh/MOF-177 was studied by pulse method. Based on further confirming the literature molecular simulation results which $\mathrm{NO}, \mathrm{O}_{2}$ and $\mathrm{CO}_{2}$ were adsorbed very little and $\mathrm{N}_{2}$ was hardly adsorbed, it was found that the MOF-177 material showed great carrier function, and promoted the atomic-sized high dispersion and stability of almost supported Rh particles on MOF-177. The adsorption properties of NO was greatly improved after Rh was introduced into MOF-177 which the adsorption capacity of $\mathrm{Rh} / \mathrm{MOF}-177$ with $3 \% \mathrm{Rh}$ loading can reach about $310 \times 10^{-3} \mathrm{mmol}\left[? \mathrm{gg}^{-1}\right.$ by pulse method and was about 15-20 times higher than that of $\mathrm{O}_{2}$ and $\mathrm{CO}_{2}$ with near $90 \%$ adsorption selectivity 
in simulated flue gas atmosphere. The NO adsorption capacity of Rh/MOF-177 was related to the reduced $\mathrm{Rh}^{0}$ which one reduced $\mathrm{Rh}^{0}$ adsorbed three NO molecules, and NO adsorption form on Rh/MOF-177 should be a trinitro-group $\left(\mathrm{Rh}(\mathrm{NO})_{3}\right)$ species.

Keywords: MOF-177;Rh component;NO adsorption properties;dispersed state;Structure-function relationship

\section{Introduction}

At present, nitrogen oxide $\left(\mathrm{NO}_{\mathrm{x}}\right)$ pollutants exhausted by flue gas of power plants and industrial kilns are mainly treated by selective catalytic reduction technology with an usual supported catalysts loaded on titanium dioxide and molecular sieve as carriers, which need to consume a large amount of reducing agent $\mathrm{NH}_{3}$ or urea, and the engineering operation cost was generally higher ${ }^{[1-2]}$. In recent years, with the development of new metal organic framework porous materials, the adsorption and separation of $\mathrm{NO}_{\mathrm{x}}$ in the flue gas has aroused the interest of researchers, intending to adsorb, separate and enrich the $\mathrm{NO}_{\mathrm{x}}$ component in the flue gas and then produce nitrate compounds such as fertilizer by desorption, oxidation and absorption, so as to achieve the resource utilization of nitrogen oxide $\left(\mathrm{NO}_{\mathrm{x}}\right)$ pollutants. For example, Yang et al. ${ }^{[3]}$ used MFM-520 metal organic framework materials (metal nodes were divalent Zn ions, organic ligands were 4,4-bipyridyl-3,3',5,5'-tetracarboxylate) to achieved efficient adsorption of $\mathrm{NO}_{2}$. At $298 \mathrm{~K}$ and $0.001 \mathrm{MPa}$, the adsorption amount of $\mathrm{NO}_{2}$ reached $4.2 \mathrm{mmol}^{*} \mathrm{~g}^{-1}$, and the IAST theoretical selectivity to $\mathrm{CO}_{2}$ was as high as 675 , at the same time, the adsorbed $\mathrm{NO}_{2}$ could be converted into $\mathrm{HNO}_{3}$ quantitatively.

More than $90 \%$ of the nitrogen oxides $\left(\mathrm{NO}_{\mathrm{x}}\right)$ in the flue gas exist in the form of $\mathrm{NO}$ component ${ }^{[1,4]}$. It has a great engineering significance to study the adsorption and separation of NO. Therefore, the adsorption and storage and separation of NO gas by MOFs has been extensively studied ${ }^{[5-11]}$. Some MOFs materials show good NO adsorbing effect through the opening metal sites and amine group functionalization. For example, the unsaturated copper atomic metal sites of HKUST-1 store and release medical NO, and the adsorption capacity of $\mathrm{NO}$ at room temperature and pressure was $3 \mathrm{mmol}^{*} \mathrm{~g}^{-1}{ }^{[6]}$. The $\mathrm{NO}$ adsorption capacity of $\mathrm{Ni}_{2}$ (dhtp) $\left(\mathrm{H}_{2} \mathrm{O}\right)_{2}{ }^{*} 8 \mathrm{H}_{2} \mathrm{O}$ (dhtp: 2, 5-dihydroxyterephthalic acid) MOFs material was $6.1 \mathrm{mmol}^{*} \mathrm{~g}^{-1}$ [10]. In general, the NO adsorption capacity of Co-CPO-27 and Ni-CPO-27 MOFs was about $6^{\sim} 7 \mathrm{mmol}^{*} \mathrm{~g}^{-1}{ }^{[7-8,}$, 12-13] After amine functionalization of MOFs materials, there was an adsorption chemical reaction between it and NO to form N-diazeniumdiate (NONOate) structure, and then conducted NO adsorption at metal sites. Therefore, MOFs also has a relatively large NO adsorption capacity, such as IRMOF-3 and UMCM$1-\mathrm{NH}_{2} \mathrm{NO}$, which respectively have $6.4 \mathrm{mmol}^{*} \mathrm{~g}^{-1}$ and $1.67 \mathrm{mmol}^{*} \mathrm{~g}^{-1}[14]$. The co-adsorption characteristics under mixed atmosphere by density functional theory (DFT) calculations showed that the NO adsorption capacity of $\mathrm{Cu}-\mathrm{BTC}$ reached the maximum $\left(10 \mathrm{mmol}^{*} \mathrm{~g}^{-1}\right)$ when the adsorption pressure was 5 atm at room temperature, but the $\mathrm{CO}_{2}$ adsorption capacity also reached the maximum $\left(21 \mathrm{mmol}^{*} \mathrm{~g}^{-1}\right)$ at $50 \mathrm{~atm}$ adsorption pressure, in other words, compared with $\mathrm{NO}$, more $\mathrm{CO}_{2}$ was adsorbed by $\mathrm{Cu}$-BTC with the adsorption pressure increasing, and the adsorption selectivity of $\mathrm{NO}$ became poor ${ }^{[15]} \cdot \mathrm{CO}_{2}$ adsorbed on M-MOF-74 ( $\mathrm{M}=\mathrm{Mg}$, Co, Ni) was difficult to be replaced by NO molecules, although NO molecules had a higher binding energy than $\mathrm{CO}_{2}$ at the MOF-74 metal sites ${ }^{[16]}$. In general, MOFs materials have shown excellent $\mathrm{NO}_{\mathrm{x}}$ adsorption and storage performance at the beginning. However, current studies mainly focus on the storage and adsorption of NO gas molecules with high purity, such as biomedical NO gas, which is at a disadvantage in competitive adsorption with other gases such as $\mathrm{CO}_{2}$ and has limited selectivity. From the point of view of engineering application, both of the adsorption selectivity and adsorption capacity of $\mathrm{NO}_{\mathrm{x}}$ are very important for the adsorption and separation of atmospheric pollutant $\mathrm{NO}_{\mathrm{x}}$ under complex atmosphere.

The MOFs materials have a developed pore structure, their skeleton can be chemically modified, and this is a higher design and adjustability in structure and performance ${ }^{[17-18]}$. As a catalyst carrier, the active center is introduced into MOFs through impregnation, deposition or adsorption to prepare highly dispersed metal or metal oxide nanoparticles with high stability, which greatly improves the adsorptive and catalytic performance of the active sites of metals ${ }^{[19-21]}$. For example, Pd nanoparticle dispersed in the pores of Pd/MIL-101, and in the process of Heck reaction of acrylic acid and selective hydrogenation of styrene, nano- 
Pd can hardly drop from MIL-101 with excellent catalytic reaction performance ${ }^{[22]}$ Pd@Cu-BDC coupling reaction ${ }^{[23]}$, Pt@UIO-66- $\mathrm{NH}_{2}$ dimensional selective hydrogenation ${ }^{[24]}$, NiMo@MIL-101 ${ }^{[25]}$ and Ru-PT@UIO$67{ }^{[26]}$ photocatalytic hydrogen evolution, etc. The high dispersion and high stability of the metal active sites, which were customized by anchoring in the MOFs material, showed excellent catalytic performance. In view of this, it is of great application significance to further improve the adsorption and separation performance of MOFs to NO gas by improving the loading of metal nanoparticles on MOFs materials.

MOF-177, as a MOFs material with small density, large specific surface area, uniform pore distribution and good thermal stability, has shown unique advantages in gas adsorption and separation ${ }^{[27-31]}$. According to the molecular simulation research results of Smit et al. ${ }^{[29]}$, at $298 \mathrm{~K}$ and $0.1 \mathrm{MPa}$, the NO adsorption capacity of MOF-177 can reached about $0.5 \mathrm{mmol}^{*} \mathrm{~g}^{-1}$, but the adsorption capacity of $\mathrm{CO}_{2}$ was also high, reached about $1.0 \mathrm{mmol}^{*} \mathrm{~g}^{-1}$, and the adsorption selectivity of $\mathrm{NO}$ was low. Because the MOF-177 was weak in $\mathrm{O}_{2}$ and $\mathrm{N}_{2}$ adsorption and can serve as a good $\mathrm{NO}$ adsorption carrier, moreover Rh active component supported on oxide carrier showed excellent selective performance for the catalytic elimination of $\mathrm{NO}_{\mathrm{x}}$ pollutants [32-33]. Therefore, if Rh is introduced into MOF-177 material to improve its NO adsorption selectivity, NO adsorption performance should be improved. This paper intends to combine noble metal Rh with porous MOF-177 material to form a composite material and explores its adsorption performance of NO in flue gas, so as to provide reference information for the purification and resource recovery of atmospheric pollutant NO.

\section{Experimental Section}

\subsection{Material preparation}

\section{(1)Carrier preparation}

MOF-177 was synthesized by solvent-thermal method ${ }^{[27]} .0 .950 \mathrm{~g}(3.193 \mathrm{mmol})$ hexahydrate zinc nitrate $\left(\mathrm{Zn}\left(\mathrm{NO}_{3}\right)_{2} * 6 \mathrm{H}_{2} \mathrm{O}, \mathrm{AR}\right), 0.190 \mathrm{~g}(0.433 \mathrm{mmol}), 1,3,5$-trisol (4-carboxyl phenyl) benzene $\left(\mathrm{H}_{3} \mathrm{BTB}, \mathrm{AR}\right)$, and $50 \mathrm{~mL}(99 \%) \mathrm{N}, \mathrm{N}$-diethylformamide (DEF) were mixed into $100 \mathrm{~mL}$ Teflon vessel and stirred until the solid was completely dissolved and the solution was pale yellow. The vessel was put into a vacuum drying oven at room temperature for $30 \mathrm{~min}$ before vacuum degassing, and then slowly put into a Teflon reaction kettle to prevent the influence of air on the reaction. The reaction kettle was placed in an electric thermostatic blast drying oven for 48 hours at $90 \operatorname{degC}$, and the temperature was cooled at $0.1 \operatorname{deg}^{*} \min ^{-1}$ rate. After taken out, the synthetic product was washed three times by ultrasonic oscillation with adding $10 \mathrm{~mL} \mathrm{DEF}$, and then separated by centrifugation. The product was continually washed for $24 \mathrm{~h}$ with adding $20 \mathrm{~mL}$ chloroform $\left(\mathrm{CHCl}_{3}\right)$ in a water bath at $70 \operatorname{deg} \mathrm{C}$ to remove the residual impurities. After removing the chloroform, the product was dried in an oven to obtain a light yellow MOF-177 crystal 。

\section{(2)Noble metal element loading and sample reduction}

Taking the above MOF-177 product as carrier, $x$ Rh/MOF-177 ( $x=1 \%, 2 \%, 3 \%$, mass fraction) was prepared by impregnation method. Taking $3 \% \mathrm{Rh} / \mathrm{MOF}-177$ as an example, $0.91 \mathrm{~g} 9 \% \mathrm{Rh}\left(\mathrm{NO}_{3}\right)_{3}$ solution was diluted with distilled water in a beaker, then $0.97 \mathrm{~g}$ MOF-177 was added into the solution and mixed well at room temperature, the mixture was stirred for $4 \mathrm{~h}$, then centrifuged. The solid was dried and calcinated for $2 \mathrm{~h}$ under air atmosphere to get $3 \% \mathrm{Rh} / \mathrm{MOF}-177$ powder.

$0.1 \mathrm{~g} \mathrm{Rh} / \mathrm{MOF}-177$ powder was put into the U-shaped quartz reaction tube and reduced for $2 \mathrm{~h}$ at $250^{\circ} \mathrm{C}$ under hydrogen flow. The reduced $x \mathrm{Rh} / \mathrm{MOF}-177$ was denoted as $\mathrm{R}-x \mathrm{Rh} / \mathrm{MOF}-177(x=1 \%, 2 \%, 3 \%$, mass fraction).

\section{$1.2 \mathrm{NO}$ pulse adsorption}

Pulse adsorption method was used to measure the pure gas adsorption capacity of Rh/MOF-177, gas signal was detected by gas chromatographic TCD detector, and gas group components were calibrated and calculated from chromatographic peak by external reference method. With the maximum pulse gas peak (i.e. adsorption saturation) as the base, the reduction amount of each pulse peak was the single adsorption 
amount, and the accumulation of the adsorption amount was the pure gas adsorption capacity. The specific process was as follows:

$0.1 \mathrm{~g}$ sample was placed to the U-shaped quartz reaction tube, and He carrier gas flow was purged at 200 ${ }^{\circ} \mathrm{C}$ until the chromatographic TCD detector baseline was stable. After the temperature dropped to room temperature (about $25{ }^{\circ} \mathrm{C}$ ), the equal flow of adsorbed gas $\left(\mathrm{NO}, \mathrm{CO}_{2}, \mathrm{O}_{2}, \mathrm{~N}_{2}\right)$ entering the reaction tube with each pulse was controlled through a six-way valve until the peak area does not change. The numerical value of gas adsorption capacity for each pulse was calculated by the difference between the integral peak area of each pulse and the peak area at adsorption saturation. The peak area of gas was calibrated by trace injection needle. For example, when $1 \mu \mathrm{L}$ NO was injected, the peak area was 0.11 , marked as $\mathrm{A}_{0}=0.11$. The adsorption capacity was calculated as follows:Finally, the adsorption capacity of gas was

Gas Storage Capacity $=\frac{\mathrm{nA}-\sum_{i=1}^{n} A_{i}}{A_{0} m} \times 10^{-3} \mathrm{~mL}^{-1}$

$A$ was the peak area of pulse saturation, $A_{\mathrm{i}}$ was the peak area of ith pulse, $A_{0}$ was the peak area calibrated, $n$ was the number of pulses, $m$ was the quality of sample.

\subsection{NO selective adsorption under mixed atmosphere}

In simulated flue gas atmosphere ( $\mathrm{NO}, \mathrm{CO}_{2}, \mathrm{O}_{2}, \mathrm{~N}_{2}$ mixture), the adsorption capacity of $\mathrm{NO}$ selectivity of Rh/MOF-177 was tested by DECRA quantitative gas analysis mass spectrometer (QGA) from Hiden company of UK. The experimental method was as follows:

The empty U-shaped quartz tube was filled with $\mathrm{N}_{2}$ flow at $200{ }^{\circ} \mathrm{C}$ to drive away other gases. When the temperature of the reaction tube dropped to room temperature, the gas flow was switched from the reaction tube to the bypass, and substituted for $20 \mathrm{ml} \cdot \mathrm{min}^{-1}$ gas mixture (1000 ppm NO, $1000 \mathrm{ppm} \mathrm{O} \mathrm{O}_{2}, 2000 \mathrm{ppm}$ $\mathrm{CO}_{2}, \mathrm{~N}_{2}$ remainder) though by-pass until QGA baseline smoothly. Then the gas mixture flow was switched to reaction tube with recording the signal of QGA. Similarly, 0.1g R-3\% Rh/MOF-177 sample was put into the U-shaped quartz reaction tube and underwent the experimental process with the same method. Adsorption and breakthrough curves of the sample were obtained after the signal of the empty tube was deducted by the signal of QGA.

\subsection{Material characterization}

The X-ray small-angle diffraction spectra of the samples were obtained using a PANalytical X'Pert ${ }^{3}$ powder diffractometer with a PIXcel detector. The X-ray generator was operated at $40 \mathrm{kV}$ and $40 \mathrm{~mA}$, using the $\mathrm{CuK} \alpha$ ray at $1.54056 \AA$ as the radiation source. Samples were scanned from $3^{\circ}$ to $80^{\circ}(2 \vartheta)$ at scanning speed of $0.1347^{\circ} \cdot \mathrm{s}^{-1}$ with a stage size of $0.02626^{\circ}$. Divergence slit: Fixed slit $1 / 32^{\circ}$; incident beam path anti-scatter slit: Fixed slit $1 / 16^{\circ}$; diffraction beam path anti-scatter slit: AS slit $7.5 \mathrm{~mm}$. The instrument used for the XPS was ESCALAB 250Xi with $\mathrm{AlK}_{\alpha}$ as the $\mathrm{X}$ source and $\mathrm{C} 1 \mathrm{~s}=284.8 \mathrm{EV}$ as the standard pollution peak to calibrate the sample charge effect. Crystal structure and morphology of the sample were characterized by high-resolution transmission electron microscope (TEM), Jeol-2100F type, under 200kV accelerating voltage. The sample was pre-treated: dissolved in absolute ethyl alcohol and dispersed in the ultrasonic instrument for 15min. The fully dispersed sample liquid drops were dropped on the copper network and dried with an infrared lamp.

\section{Results and Discussion}

\subsection{Structure and thermal stability of the synthesized products}

MOF-177 was synthesized according to the method in reference ${ }^{[27]}$, and Rhodium component was carried on it. Figure 1 showed the XRD pattern of MOF-177, the main peaks at $5.7^{\circ}$ and $10.5^{\circ}$ were well identified. The XRD structure was consistent with that in reference ${ }^{[27]}$, indicating that the samples prepared in this work should be MOF-177 frame structure compounds. However, crystal lattice changes slightly such as loaded crystal particles become smaller due to the peak at $10.5^{\circ}$ was wider than without load samples in XRD pattern of $1 \%-3 \%$ Rh/MOF-177. 
The weight loss of MOF-177, 3\% Rh/MOF-177 and R-3\% Rh/MOF-177 measured by the thermo-gravimetric method (TG) under $\mathrm{N}_{2}$ atmosphere were shown in Figure 2. It can be seen that the weight loss curves of the three MOFs were basically the same, and the thermal stability of MOF-177 was higher than that of $3 \%$ $\mathrm{Rh} / \mathrm{MOF}$ and R-3\% Rh/MOF-177. The weight loss process was divided into three stages, $3 \% \mathrm{Rh} / \mathrm{MOF}-177$ and R-3\% Rh/MOF-177 lost $10 \%$ and $6.6 \%$ respectively between $50{ }^{\circ} \mathrm{C}$ and $331{ }^{\circ} \mathrm{C}$, and MOF- 177 lose $15.8 \%$ between $50{ }^{\circ} \mathrm{C}$ and $427{ }^{\circ} \mathrm{C}$ which was $96{ }^{\circ} \mathrm{C}$ higher than the thermal stability of the material after loading. The first two stages of weight loss could be attributed to the volatilization of guest molecules $\mathrm{H}_{2} \mathrm{O}$ and DEF. There were obvious differences among the three in the third stage. A drastic weight loss by heating from $427{ }^{\circ} \mathrm{C} \sim 540{ }^{\circ} \mathrm{C}$ was observed due to decomposition of MOF-177. 3\% Rh/MOF-177 and R-3\% Rh/MOF- 177 gradually decomposed and collapsed at $331{ }^{\circ} \mathrm{C} \sim 450{ }^{\circ} \mathrm{C}$. TG results showed that better thermal stability of MOF-177 and the loaded Rh/MOF-177 were all above $330{ }^{\circ} \mathrm{C}$.

\subsection{Adsorption of NO by Rh/MOF-177}

MOF-177 has been proved to have a relatively limited adsorption capacity by Smit ${ }^{[29]}$ and Saha ${ }^{[30]}$ et al. according to GCMC molecular simulation technology. Figure 3 showed adsorption capacity of NO on MOF177 measured by pulse method at 298K. Through the peak area integral, it can be seen that MOF-177 had a trace adsorption of NO, which was due to its high specific surface area and large porosity ${ }^{[34-37]}$. NO adsorption capacity of MOF-177 material by calculating was $3.3 \times 10^{-2} \mathrm{~mL} \cdot \mathrm{g}^{-1}\left(1.35 \times 10^{-3} \mathrm{mmol} \cdot \mathrm{g}^{-1}\right)$. This was smaller than the results reported in literature molecular simulation (at $298 \mathrm{~K}$ and $0.1 \mathrm{MPa}$ ) for 0.5 $\mathrm{mmol} \cdot \mathrm{g}^{-1}[29]$. It can be speculated that partial pressure of the adsorbent in He airflow decreased and was too smaller after the pulsing of NO.

Excellent catalytic performance was showed in removal of $\mathrm{NO}_{\mathrm{x}}$ pollutants of $\mathrm{Rh}$ active component supported on oxide carriers ${ }^{[32-33]}$. In this work, $\mathrm{Rh} / \mathrm{MOF}-177$ was prepared with different $\mathrm{Rh}$ loadings and tested the adsorption performance of $\mathrm{NO}$ at room temperature in order to improve the NO adsorption and separation performance of MOF-177 in flue gas. The results were shown in Figure 4, Figure 5 and Table 2. It can be seen from Figure 4 and Figure 5 that the adsorption capacity of R-1\% Rh/MOF-177 and R-3\% Rh/MOF-177 was basically close to that of $1.24 \mathrm{ml} \cdot \mathrm{g}^{-1}$ and $1.18 \mathrm{ml} \cdot \mathrm{g}^{-1}$ respectively when the sample was injected in the first pulse. While the adsorption capacity of R-2\% Rh/MOF-177 was $1.98 \mathrm{ml} \cdot \mathrm{g}^{-1}$, which was about 1.6 times that of R-1\% Rh/MOF-177. During the 2-4 injection periods, the adsorption rate of R-1\% Rh/MOF- 177 gradually decreased, and the adsorption amount remained unchanged after the fifth injection, indicating that the adsorption was saturated. the total NO adsorption amount of $\mathrm{R}-1 \% \mathrm{Rh} / \mathrm{MOF}-177$ was $2.57 \mathrm{~mL} \cdot \mathrm{g}^{-1}$. The adsorption rate of $\mathrm{R}-2 \% \mathrm{Rh} / \mathrm{MOF}-177$ was the largest among all the samples before the fourth pulse, but after the fourth pulse, it gradually decreased and lowered than R-3\% Rh/MOF-177. After the seventh pulse, the curve was basically stable, R-3\% Rh/MOF-177 reached its saturation state, the total adsorption volume of $\mathrm{NO}$ was $5.45 \mathrm{~mL} \cdot \mathrm{g}^{-1}$. R-3\% Rh/MOF-177 adsorbed $\mathrm{NO}$ at most, up to $7.55 \mathrm{~mL} \cdot \mathrm{g}^{-1}$. It can be seen that the adsorption performance of $\mathrm{NO}$ on the loaded Rh of MOF-177 was greatly improved. In addition, the adsorption capacity of unreduced $3 \% \mathrm{Rh} / \mathrm{MOF}-177$ to NO had only $0.12 \mathrm{~mL} \cdot \mathrm{g}^{-1}$ which was not significantly increased compared with MOF-177. The adsorption performance of R-Rh/MOF-177 after the reduction of $\mathrm{H}_{2}$ at $250{ }^{\circ} \mathrm{C}$ for $2 \mathrm{~h}$ was significantly improved compared with that of non-reduced materials, which indicated that NO adsorption occurred on metallic Rh particles rather than Rh ions. A large amount of NO gas was adsorbed on R-3\% Rh/MOF-177 whom has the strongest adsorption performance after 16 pulses in total. The result showed Rh/MOF-177 can improved the NO adsorption performance of the material. With the increasing of the Rh loading, the capacity of NO adsorption of R-Rh/MOF-177 was gradually enhanced as well as the performance of NO adsorption was significantly improved. From the table 2, it can be seen the adsorption capacity of $\mathrm{NO}$ on R-Rh/MOF-177 was basically proportional to the Rh loading capacity, and was much larger than samples without reduction as well as MOF-177 after converted the total NO adsorption volume unit for each sample into a molar value. So it was clear that there should be a directly relate between total adsorption value of $\mathrm{NO}$ on R-Rh/MOF-177 and the quantity of metallic Rh components loading.

XPS and TEM were used to characterize the samples in order to explore the structure-function relationship between the chemical and dispersion state and NO adsorption characteristics of R-Rh/MOF-177. Figure 6 
was the XPS spectrum of Rh $3 d$ state electron energy level. The peak separation of Rh $3 d$ spectrum showed that the binding energy of Rh/MOF-177 was located at 304-320 eV, For $\mathrm{Rh} 3 d_{5 / 2}$ spectrum, $\mathrm{Rh}^{3+}$ and $\mathrm{Rh}^{0}$ peaks occur at $309.0 \mathrm{eV}$ and $307.8 \mathrm{eV}$, respectively ${ }^{[36]}$. In Table 3, the relative contents of $\mathrm{Rh}$ components in different valence states were obtained by calculating the peak area. From Table 3 it can be seen that $\mathrm{Rh}^{3+}$ was the main existing form in the unreduced $\mathrm{Rh} / \mathrm{MOF}-177$ samples, and $\mathrm{Rh}^{0}$ appears after reduction. After reducing, the proportion of $\mathrm{Rh}^{0}$ was $29.4 \%^{\sim} 36.2 \%$ and $\mathrm{Rh}^{3+}$ was $63.8^{\sim} 70.6 \%$. With the increasing of $\mathrm{Rh}$ loading, the content of $\mathrm{Rh}^{0}$ gradually increased. Combined with $\mathrm{NO}$ adsorption characteristics, it can clearly demonstrate that metallic $\mathrm{Rh}^{0}$ made a major role in NO adsorption after reducing by XPS results. The loaded $\mathrm{Rh}$ provided more unsaturated metal sites for gas adsorption of materials, then $\mathrm{Rh}^{0}$ played a major role in adsorption which reduced direct decomposition activation energy of $\mathrm{NO}$ greatly ${ }^{[38]}$. The molar ratios of adsorption values for $\mathrm{Rh}^{0}$ and $\mathrm{NO}$ can be obtained by calculating (Table 3). The adsorption ratios of R-1\% Rh/MOF-177, R-2\% Rh/MOF-177 and R-3\% Rh/MOF-177 were basically the same for 1:3, 1:4 and 1:3.3 respectively. Overall, three NO molecules were adsorbed by one reducing state of $\mathrm{Rh}^{0}$ approximately considering the experimental error.

Figure $7 \mathrm{a}, \mathrm{b}$ and c were TEM images of MOF-177 (under $20 \mathrm{~nm}$ scale), R-1\% Rh/MOF-177(under $10 \mathrm{~nm}$ scale) and R-3\% Rh/MOF-177(under $10 \mathrm{~nm}$ scale) respectively. It can be seen that the black dot shadow in Figure $7 \mathrm{~b}$ and $\mathrm{c}$ should be the Rh metal particle by comparing Figure 7 a. The comparison among Figure $7 \mathrm{a}, \mathrm{b}$ and $\mathrm{c}$ turned that the metal particle was homogeneous distribution and the diameter of $\mathrm{Rh}$ metal particle was approximately the same as the diameter of Rh atom, about $1.6 \mathrm{~nm}$ measured by DM (Digital Micrograph) software. With the increasing of the Rh, the density of shadow increased, but it still distributed evenly. It could indicate that the metal particles did not agglomerate after loading $\mathrm{Rh}$, and the dispersion was relatively stable after the reduction at $250{ }^{\circ} \mathrm{C}$. Form Figure $7 \mathrm{~d}$-g element mapping, $\mathrm{Rh}$ element was marked as red and $\mathrm{Zn}$ was represented by purple. When the load only $1 \%$, the $\mathrm{Zn}$ element was dense and $\mathrm{Rh}$ was dispersed; when the load was increased to $3 \%$, the overall density of $\mathrm{Zn}$ element and Rh element was much higher than that of samples 1\% loading. Because of the gap between the crystal particles of MOF-177, $\mathrm{Rh}$ element was dense and $\mathrm{Zn}$ element was dispersed at the graph. As there was no $\mathrm{Zn}$ element but $\mathrm{Rh}$ element in MOF-177. By observing TEM and element mapping, MOF-177 as a carrier can make the Rh components have homogeneous distribution and highly stable. In addition, the larger specific surface area and porosity provided a better condition for the adsorption of NO for R-Rh/MOF-177

\subsection{NO adsorption selectivity}

Although R-2\% Rh/MOF-177 showed excellent NO adsorption capacity in the first three injections, in terms of the overall adsorption capacity, R-3\% Rh/MOF-177 was superior. Through calculation, R-3\% Rh/MOF177 had the largest adsorption of NO, the total of $7.55 \mathrm{ml} \cdot \mathrm{g}^{-1}$. Therefore, R-3\% Rh/MOF-177 was selected to explore the adsorption selectivity of $\mathrm{NO}$ at room temperature and atmospheric pressure. Figure 8 showed the pulse adsorption of $\mathrm{O}_{2}, \mathrm{CO}_{2}$ and $\mathrm{N}_{2}$ respectively by MOF-177 and R-3\% Rh/MOF-177 at the same pressure and temperature. Figure 9 showed the pulse adsorption trend of MOF-177 (left) and the pulse adsorption trend of R-3\% Rh/MOF-177 (right). Combined with the two figures, it can be seen that MOF-177 basically does not adsorbed $\mathrm{N}_{2}$ and $\mathrm{CO}_{2}$, and its adsorption capacity was approximately 0 , and its adsorption capacity for $\mathrm{O}_{2}$ was only $0.032 \mathrm{ml} \cdot \mathrm{g}^{-1}$, and its adsorption capacity for $\mathrm{NO}$ was also relatively low. The adsorption of $\mathrm{CO}_{2}$ and $\mathrm{N}_{2}$ by R-3\% Rh/MOF-177 after loading Rh showed little change, and the adsorption amount of MOF-177 was negligible compared with MOF-177. The adsorption amount of $\mathrm{O}_{2}$ was increased, which was about $1.26 \mathrm{~mL} \cdot \mathrm{g}^{-1}$ after calculation. However, compared with the $7.55 \mathrm{~mL} \cdot \mathrm{g}^{-1}$ adsorption amount of NO by R-3\% Rh/MOF-177, its $\mathrm{O}_{2}$ adsorption was relatively weak. The single component pulsed adsorption results showed that R-Rh/MOF-177 had the best selective adsorption effect on NO.

The selective adsorption of NO by R-3\% Rh/MOF-177 in NO, $\mathrm{CO}_{2}, \mathrm{O}_{2}, \mathrm{~N}_{2}$ mixture (1000 ppm NO, 1000 ppm $\mathrm{O}_{2}, 2000 \mathrm{ppm} \mathrm{CO}_{2}, \mathrm{~N}_{2}$ remainder) was verified by DECRA quantitative gas analysis mass spectrometer. $0.1 \mathrm{~g} \mathrm{R}-3 \% \mathrm{Rh} / \mathrm{MOF}-177$ was put into the U-shaped reaction tube. After $\mathrm{N}_{2}$ pretreatment, $20 \mathrm{~mL} \cdot \mathrm{min}^{-1}$ mixture was injected. The adsorption curve and penetration curve were shown in Figure 10 (a) and Figure 10 (b), respectively. It can be seen from the figure, the signal changed in 8 min after the mixture was 
fed into the reaction tube, $\mathrm{O}_{2}$ and $\mathrm{CO}_{2}$ were adsorbed and saturated in 12 min and 16 min respectively, and their concentrations quickly return to the intake value. The adsorption capacities of $\mathrm{O}_{2}$ and $\mathrm{CO}_{2}$ were $4.9 \times 10^{-3}$ and $6.9 \times 10^{-3} \mathrm{mmol} \cdot \mathrm{g}^{-1}$ respectively. During10-12 min, NO signal was at its lowest and appears on the platform, and it slowly returns to the intake gas at $12-45 \mathrm{~min}$. The concentration was close to adsorption saturation, and the adsorption capacity reached about $100 \times 10^{-3} \mathrm{mmol} \cdot \mathrm{g}^{-1}$, which was $15-20$ times that of $\mathrm{O}_{2}$ and $\mathrm{CO}_{2}$. Although adsorption experimental results of $\mathrm{NO}, \mathrm{CO}_{2}, \mathrm{O}_{2}, \mathrm{~N}_{2}$ under the mixture had decreased, its adsorption characteristics and the pulse results of Rh/MOF-177 for $\mathrm{NO}, \mathrm{CO}_{2}, \mathrm{O}_{2}$ were consistent with single component adsorptive properties. A little of $\mathrm{CO}_{2}$ and $\mathrm{O}_{2}$ were absorbed, but large quantity of $\mathrm{NO}$ was collected. These results further verified the selectivity to the adsorption of NO. By calculation, the adsorption selectivity of NO in mixed atmosphere was about $89.45 \%$. The experimental results showed that greatly enhancement of $\mathrm{NO}$ adsorption capacity and adsorption selectivity by introducing the Rh to MOF177 material, and there were significant improvements of $\mathrm{NO}$ adsorption performance. As for $\mathrm{NO}_{\mathrm{x}}$ in flue gas adsorption separation and then to stripping oxidation of absorbing compounds nitrate, this result should have large potential of air pollutants purification and recycling application of NO.

\subsection{The structure-function relationship}

The experimental results of this work showed that the adsorption property of NO was significantly improved after Rh was introduced into MOF-177, showing high NO adsorption capacity and adsorption selectivity. The pulse-method adsorption capacity of $\mathrm{NO}$ for the Rh/MOF-177 with a load of $3 \% \mathrm{Rh}$ can reached about $310 \times 10^{-3} \mathrm{mmol} \cdot \mathrm{g}^{-1}$, far higher than $\mathrm{O}_{2}$ and $\mathrm{CO}_{2}$ adsorption amount (about 15 to 20 times more), NO adsorption selectivity was up to near $90 \%$ under mixed atmosphere, this was just only on the $30 \%$ reduction degree of $\mathrm{Rh}$ components and the lower adsorption concentration or partial pressure conditions. Oxides such as adsorption materials supported on $\mathrm{Al}_{2} \mathrm{O}_{3}$ and zeolite carrier, its $\mathrm{NO}$ adsorption capacity under atmospheric pressure was usually $0.06^{\sim} 0.096 \mathrm{mmol} \cdot \mathrm{g}^{-1[40]}$, which was relatively limited. This indicated that MOF-177 material was an excellent carrier, which can provide better NO adsorption performance by introducing the active component $\mathrm{Rh}$ and so on, showed good carrier function. Because the thermal stability of $\mathrm{Rh} / \mathrm{MOF}-177$ was good to reach above $330{ }^{\circ} \mathrm{C}$, this also created the application basis for the adsorption separation and enrichment of $\mathrm{NO}_{\mathrm{x}}$ in the flue gas.

In general, the adsorption of NO by transition metal components loaded on oxide carriers is usually manifested as surface disproportionation reaction adsorption, and the formation of species such as $\mathrm{N}_{2} \mathrm{O}_{4}, \mathrm{NO}_{2}, \mathrm{NO}_{3}$ - or $\mathrm{NO}_{2}$ - promotes the adsorption of $\mathrm{NO}{ }^{[41-42]}$, and the higher the valence state, the weaker the adsorption of $\mathrm{NO}{ }^{[43]}$. Species nitroso $\mathrm{Rh}(\mathrm{NO})$ and dinitro $\mathrm{Rh}(\mathrm{NO})_{2}$ are formed when $\mathrm{NO}$ is absorbed by $\mathrm{Rh}$ component with $\mathrm{Al}_{2} \mathrm{O}_{3}$ as the carrier [39-40,44]. The experimental results of this work showed that about one reduced state $\mathrm{Rh}^{0}$ on $\mathrm{Rh} / \mathrm{MOF}-177$ adsorbed three NO molecules, and it could be speculated that NO adsorption on $\mathrm{Rh} / \mathrm{MOF}-177$ formed an adsorptive state trinitro group $\left(\mathrm{Rh}(\mathrm{NO})_{3}\right)$ species, which was different from the results of NO adsorption machine in the existing literature. The outer-shell electron structure of $\mathrm{Rh}$ atom is $4 \mathrm{~d}^{8} 5 \mathrm{~s}^{1}$, and there are three unpaired electrons in the $4 \mathrm{~d}$ and $5 \mathrm{~s}$ orbitals, so it may be that the reduced state $\mathrm{Rh}^{0}$ on $\mathrm{Rh} / \mathrm{MOF}-177$ adsorbed $\mathrm{NO}$ and formed linear Rh-NO or Rh-N=O adsorption modes. The generation of these species resulted the higher adsorption capacity of Rh/MOF-177 to NO gas.

Some MOFs materials showed a better adsorption effect to pure NO molecule through opening various metal sites and amine group functionalization. In general, NO and unsaturated metal sites typically form 1:1 coordination, and there is also possible to form N-diazeniumdiolate(NONOate)structure through adsorptive chemical reactions between functionalized amine groups and NO, and then the adsorption was performed on the metal sites, exhibiting larger NO adsorption capacity, and there are NO chemical adsorption and physical adsorption on MOFs materials ${ }^{[7-9,12-14]}$. However, when most MOFs materials adsorb NO, they will also absorb more $\mathrm{CO}_{2}$, with poor selectivity ${ }^{[15-16]}$. MOF-177 is composed of $\mathrm{Zn}$ ionic metal nodes and 1,3, 5-trisol (4-carboxyl phenyl) benzene $\left(\mathrm{H}_{3} \mathrm{BTB}\right)$ ligand. The calculation results of molecular simulation also showed that MOF-177 had a certain adsorption capacity for NO under certain conditions, and its adsorption for $\mathrm{CO}_{2}$ and $\mathrm{O}_{2}$ was very limited ${ }^{[29-30]}$. The experimental results of this work also verified this phenomenon. According to the results of high-resolution transmission electron microscope (TEM) and 
Rh3delectron energy level XPS, the topological space structure of Rh/MOF-177 can be inferred as shown in Figure 11. With different from the reported NO adsorption mechanism of these MOFs materials, the NO adsorption model of Rh/MOF-177 materials changed greatly after the loading of Rh component - that is, one reduced $\mathrm{Rh}^{0}$ adsorbed three NO molecules and the NO adsorption form on Rh/MOF-177 should be a trinitrogroup $\left(\mathrm{Rh}(\mathrm{NO})_{3}\right)$ adsorbed species. This resulted in significantly enhanced NO adsorption performance of Rh/MOF-177, which not only NO adsorption capacity significantly increased but also selectivity increased. According to the results of high-resolution transmission electron microscope (TEM), the Rh particles reduced at $250 \operatorname{deg} \mathrm{C}$ with different load of Rh components were basically atomic-sized dispersion state with good stability. This was due to the larger specific surface area and porosity of MOF-177, which provided a better carrier function for the high dispersion and stability of Rh component.

\section{Conclusion}

The experimental adsorption capacity of MOF-177 for $\mathrm{NO}, \mathrm{O}_{2}$ and $\mathrm{CO}_{2}$ by pulse method was very small and $\mathrm{N}_{2}$ was hardly adsorbed at room temperature, which was consistent with the molecular simulation calculation results in the literature. The introduction of Rh component in MOF-177 can significantly improve its NO adsorption performance, showed high NO adsorption capacity and adsorption selectivity. The NO adsorption capacity increased with the increase of $\mathrm{Rh}$ load and was related to the reduced state $\mathrm{Rh}^{0}$. The adsorption capacity of NO by pulse method can reach about $310 \times 10^{-3} \mathrm{mmol}^{*} \mathrm{~g}^{-1}$ when $3 \% \mathrm{Rh} / \mathrm{MOF}-177$ was reduced for $2 \mathrm{~h}$ at $250 \mathrm{degC}$. The adsorption capacity of NO in simulated flue gas atmosphere was about 15-20 times higher than that of $\mathrm{O}_{2}$ and $\mathrm{CO}_{2}$, and the adsorption selectivity was up to near $90 \%$.

The experimental results showed that one reduced state $\mathrm{Rh}^{0}$ adsorbed three NO molecules, and the NO adsorption on $\mathrm{Rh} / \mathrm{MOF}-177$ should be the adsorption state trinitro-group $\left(\mathrm{Rh}(\mathrm{NO})_{3}\right)$ species. After reduction at $250 \mathrm{degC}$, the Rh particles in the MOF-177 exhibited atomic-size dispersion with good stability, and the MOF-177 material showed good carrier function.

\section{Reference}

[1] Busca G, Lietti L, Ramis G, Berti F. Chemical and mechanistic aspects of the selective catalytic reduction of $\mathrm{NO}_{\mathrm{x}}$ by ammonia over oxide catalysts [J]. Applied Catalysis B: Environmental. 1998, 18(1-2): 1-36. [2] Chen M-Y, Zhao M-M, Tang F-S, Ruan L, Yang H-B, Li N. Effect of Ce doping into $\mathrm{V}_{2} \mathrm{O}_{5^{-}}$ $\mathrm{WO}_{3} / \mathrm{TiO}_{2}$ catalysts on the selective catalytic reduction of $\mathrm{NO}_{\mathrm{x}}$ by $\mathrm{NH}_{3}$. Journal of Rare Earths. 2017, 35(12): 1206-1215. [3] Li J-N, Han X, Zhang X, Sheveleva AM, Cheng YQ, Tuna F, McInnes Eric JL, Laura JM, Teat SJ, Luke LD, Ramirez AJ., Schroder M and Yang S-H. Capture of nitrogen dioxide and conversion to nitric acid in a porous metal-organic framework. Nature Chemistry. 2019, 11: 1085-1090. [4] Tang F-S, Zhuang K, Yang F, Yang L, Xu B-L, Qiu J-H, Fan YN. Effect of dispersion state and surface properties of supported vanadia on the activity of $\mathrm{V}_{2} \mathrm{O}_{5} / \mathrm{TiO}_{2}$ catalysts for the selective catalytic reduction of $\mathrm{NO}$ by $\mathrm{NH}_{3}$. Chinese Journal of Catalysis. 2012, 33(6): 933-940.

[5] Zhang Z-Q, Atkinson JD, Jiang B-Q, Roodb MJ, Yan Z-F. Nitric oxide oxidation catalyzed by microporous activated carbon fiber cloth: An updated reaction mechanism [J]. Applied Catalysis B: Environmental. 2014, 148(27): $573-581$.

[6] Xiao B, Wheatley PS, Zhao X-B, Fletcher AJ, Fox S, Rossi AG, Megson I L, Bordiga S, Thomas L, and Morris RE. High-capacity hydrogen and nitric oxide adsorption and storage in a metal-organic framework. [J]. Journal of the American Chemical Society. 2007, 129(5): 1203-1209.

[7] McKinlay AC, Xiao B, Wragg D, Wheatley PS, Megson IL., and Morris RE. Exceptional behavior over the whole adsorption-storage-delivery cycle for NO in porous metal organic frameworks $[\mathrm{J}]$. Journal of the American Chemical Society. 2008, 130(31): 10440-10444.

[8] Cattaneo D, Warrender SJ, Duncan MJ, Castledine R, Parkinson N, Haley I and Morris RE. Water based scale-up of CPO-27 synthesis for nitric oxide delivery [J]. Dalton transactions. 2016, 45(2): 618-629.

[9] Barth B, Mendt M, Poppl A, Hartmann M. Adsorption of nitric oxide in metal-organic frameworks: 
Low temperature IR and EPR spectroscopic evaluation of the role of open metal sites [J]. Microporous and Mesoporous Materials. 2015, 216: 97-110.

[10] Bonino F, Chavan S, Vitillo JG, Groppo E, Agostini G, Lamberti C, Dietzel PD, Prestipino C, and Bordiga S. Local structure of CPO-27-Ni metal organic framework upon dehydration and coordination of NO [J]. Chemistry of Materials: A Publication of the American Chemistry Society. 2008, 20(15): 4957-4968.

[11] Li B, Wen H-M, Cui Y-J, Zhou W, Qian G-D, Chen B-L. Emerging multifunctional metal-organic framework materials. Advanced Materials. 2016, 28: 8819-8860.

[12] Dietzel PD, Morita Y, Blom R, and Fjellvag H. An in situ high-temperature single-crystal investigation of a dehydrated metal-organic framework compound and field-induced magnetization of one-dimensional metal-oxygen chains [J]. Angewandte Chemie. 2005, 44(39): 6354-6358.

[13] Dietzel PD, Panella B, Hirscher M, Blom R and Fjellvag H. Hydrogen adsorption in a nickel based coordination polymer with open metal sites in the cylindrical cavities of the desolvated framework [J]. Chemical Communications. 2006, 9: 959-961.

[14] Nguyen JG, Tanabe KK and Cohen SM. Postsynthetic diazeniumdiolate formation and NO release from MOFs [J]. CrystEngComm. 2010, 12(8): 2335-2338.

[15] Meng G-H, SongX-D, Ji M, Hao J-Y, Shi Y-T, Ren S-Z, Qiu J-S, Hao C. Molecular simulation of adsorption of $\mathrm{NO}$ and $\mathrm{CO}_{2}$ mixtures by a $\mathrm{Cu}-\mathrm{BTC}$ metal organic framework [J]. Current Applied Physics the Official Journal of the Korean Physical Society. 2015, 15(9): 1070-1074.

[16] Tan K, Zuluaga S, Gong Q, Gao Y-Z, Nijem N, Ji L, Thonhauser T, and Chabal YJ. Competitive coadsorption of $\mathrm{CO}_{2}$ with $\mathrm{H}_{2} \mathrm{O}, \mathrm{NH}_{3}, \mathrm{SO}_{2}, \mathrm{NO}, \mathrm{NO}_{2}, \mathrm{~N}_{2}, \mathrm{O}_{2}$, and $\mathrm{CH}_{4}$ in M-MOF-74 $(\mathrm{M}=\mathrm{Mg}, \mathrm{Co}, \mathrm{Ni})$ : the role of hydrogen bonding. Chemistry of Materials. 2015, 27(6): 2203-2217.

[17] Li B, Wen H-M, Yang Y Cui Y-J, Zhou W, Chen B-L, Qian G-D. Nanospace within metal-organic frameworks for gas storage and separation. Materials Today Nano. 2018, 2: 21-49.

[18] Pei J-Y, Shao K, Wang J-X, Wen H-M, Yang Y, Cui Y-J, Krishna R, Li B and Qian G-D. A chemically stable hofmann-type metal-organic framework with sandwich-like binding sites for benchmark acetylene capture. [J]. Advanced Materials. 2020, 32: 1908275.

[19] Tang F-S, Zhao J and Chen B-L. Porous coordination polymers for heterogeneous catalysis. Current Organic Chemistry. 2018, 22(18): 1773-1791.

[20] Huang H-G, Shen K, Chen F and Li Y-W. Metal-organic frameworks as a good platform for the fabrication of single-atom catalysts[J]. ACS Catalysis. 2020, 10: 6579-6586.

[21] Chen X-D, ShenK, Ding D-N, Chen J-Y, Fan T, WuR-F, Li Y-W. Solvent-driven selectivity control to either anilines or dicyclohexylamines in hydrogenation of nitroarenes over a bifunctional Pd/MIL-101 catalyst[J]. ACS Catalysis, 2018, 8(11): 10641-10648.

[22] Henschel A, Gedrich K, Kraehnert R and Kaskel S.Catalytic properties of MIL-101.Chem. Comm. 2008, 44(35): 4192-4192. [23] Annapurna M, Parsharamulu T, Reddy VP, Suresh M, Likhar PR and Kantam ML. Nano palladium supported on high-surface-area metal-organic framework MIL-101: an efficient catalyst for Sonogashira coupling of aryl and heteroaryl bromides with alkynes. Applied Organometallic Chemistry. 2015, 29(4): 234-239. [24] Chen Y-F, Tan L-L, Liu J-M, Qin S, Xie Z-Q, Huang J-F, Xu Y-W, Xiao L-M, Su C-Y. Calix[4] arene based dye-sensitized Pt@UiO-66- $\mathrm{NH}_{2}$ metal-organic framework for efficient visible-light photocatalytic hydrogen production. Applied Catalysis B: Environmental. 2017, 206, 426-433. [25] Zhen W-L, Gao H-B, Tian B, Ma and Lu G-X. Fabrication of low adsorption energy Ni-Mo cluster cocatalyst in metal-organic frameworks for visible photocatalytic hydrogen evolution. ACS Appl. Mater. Interfaces. 2016, 8(17): 10808-10819. [26] Hou C-C, L T-T, Cao S, Chen Y, and Fu W-F. Incorporation of a $\left[\mathrm{Ru}(\text { dcbpy })(\text { bpy })_{2}\right]^{2+}$ photosensitizer and a $\mathrm{Pt}(\mathrm{dcbpy}) \mathrm{Cl}_{2}$ catalyst into metal-organic frameworks for pho- 
tocatalytic hydrogen evolution from aqueous solution [J]. Journal of Materials Chemistry A. 2015, 3(19): 10386-10394.

[27] Chae HK, Siberio-Pe'rez DY, Kim J, Go YB, Eddaoudi M, Matzger A J, O'Keeffe M, Yaghi OM. A route to high surface area, porosity and inclusion of large molecules in crystals [J]. Nature. 2004, 427(6974): $523-527$.

[28] Li Y-W, Yang RT. Gas adsorption and storage in metal-organic framework MOF-177. [J] Langmuir. 2007, 23(26):12937-12944.

[29] Sun W-Z, Lin L-C, Peng X, Smit B. Computational screening of porous metal-organic frameworks and zeolites for the removal of $\mathrm{SO}_{2}$ and NOx from flue gases. [J]. AIChE Journal. 2014, 60(6): 2314-2323.

[30] Saha D, Bao Z, Jia F and Deng S-G. Adsorption of $\mathrm{CO}_{2}, \mathrm{CH}_{4}, \mathrm{~N}_{2} \mathrm{O}$, and $\mathrm{N}_{2}$ on MOF-5, MOF-177, and zeolite 5A. Environmental Science and Technology. 2010, 44(5): 1820-1826.

[31] Yang K, Xue F, Sun Q, Yue R-L, Lin D-H. Adsorption of volatile organic compounds by metal-organic frameworks MOF-177 [J]. Journal of Environmental Chemical Engineering. 2013, 1(4): 713-718.

[32] Cao Y-D, Ran R, Wu X-D, Zhao B-H and Weng D. Improved activity and durability of Rh-based threeway catalyst under diverse aging atmospheres by $\mathrm{ZrO}_{2}$ support [J]. Journal of Environmental Sciences. 2017, 52: 197-203.

[33] Fu M-L, Ye D-Q, Liang H. Effect of the Rhodium content on the performance of supported nobel metal three-way catalysts[J]. Preious Metals, 2002, 23(2): 6-10.

[34] Panella BB, Hirscher M, Putter H, and Muller U. Hydrogen adsorption in metal-organic frameworks: $\mathrm{Cu}-\mathrm{MOFs}$ and Zn-MOFs compared [J]. Advanced Functional Materials. 2006, 16(4): 520-524.

[35] Furukawa H, Miller MA and Yaghi OM. Independent verification of the saturation hydrogen uptake in MOF-177 and establishment of a benchmark for hydrogen adsorption in metal-organic frameworks[J]. Journal of Materials Chemistry. 2007, 17(30): 3197-3204.

[36] Kondarides DI, Verykios XE. Effect of chlorine on the chemisorptive properties of $\mathrm{Rh} / \mathrm{CeO}_{2}$ catalysts studied by XPS and temperature programmed desorption techniques[J]. Journal of Catalysis, 1998, 174(1):5264 .

[37] Rowsell JLC, Yaghi OM. Metal-organic frameworks: a new class of porous materials [J]. Microporous and Mesoporous Materials. 2004, 73(1-2): 3-14.

[38] Tu X-Y, Tian K, Dai S-S. Density function study of NO adsorption and direct decomposition on Rh(100) and $\operatorname{Rh}(111)$ surfaces [J]. Chemical journal of Chinese universities. 2005, 26(12): 2354-2356.

[39] Newton MA, Dent AJ, Fiddy SG, Jyoti B and Evans J. Identification of the surface species responsible for $\mathrm{N}_{2} \mathrm{O}$ formation from the chemisorption of $\mathrm{NO}$ on Rh/alumina $[\mathrm{J}]$. Physical chemistry chemical physics, 2007, 9(2):246-249.

[40] Liang J, Wang H-P, Spicer L-D. FT-IR study of nitric oxide chemisorbed on Rh/ $\mathrm{Al}_{2} \mathrm{O}_{3}$ [J]. The Journal of Physical Chemistry. 1985, 89(26): 5840-5845.

[41] Mul G, Perez-Ramirez J, Kapteijn F and Moulijin JA. NO Adsorption on ex-framework [Fe,X]MFI catalysts: novel IR bands and evaluation of assignments [J]. Catalysis Letters. 2002, 80(3): 129-138.

[42] Kang H-X, Guo Q-H, Li J-W, Li Y-X. The investigation of both NO and $\mathrm{N}_{2} \mathrm{O}$ adsorption and NOassisted action to $\mathrm{N}_{2} \mathrm{O}$ decomposition mechanism over Fe-ZSM-5 zeolite [J]. Journal of Henan University (Natural Science). 2008, 38(03): 261-265.

[43] Zhu C-Y, Fu J, Du L-C, Li Q-Z. Studies on the adsorption of NO on Fe(III)/Y zeolite by FT-IR method [J]. Chinese Science Bulletin. 1994, 39(22): 2055-2058. 
[44] Li G-X, Huang Q-Z, Hou J. NO adsorption activity of Pt supported on activated carbon fiber [J]. Chinese Journal of Catalysis. 2003, 24(2): 107-110.

\section{Hosted file}

Table.pdf available at https://authorea.com/users/371914/articles/490103-study-on-noselective-adsorption-performance-of-rh-mof-177
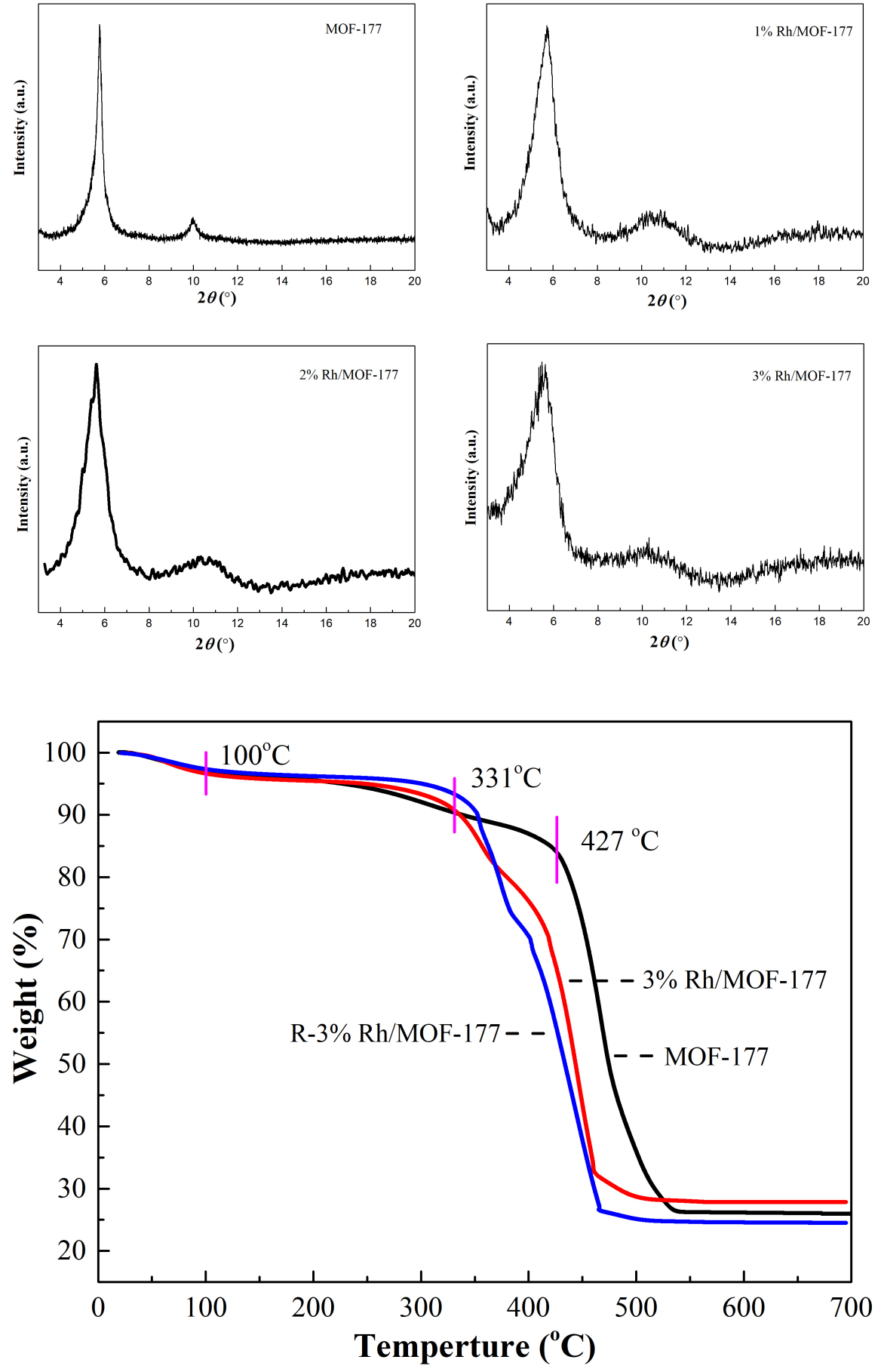

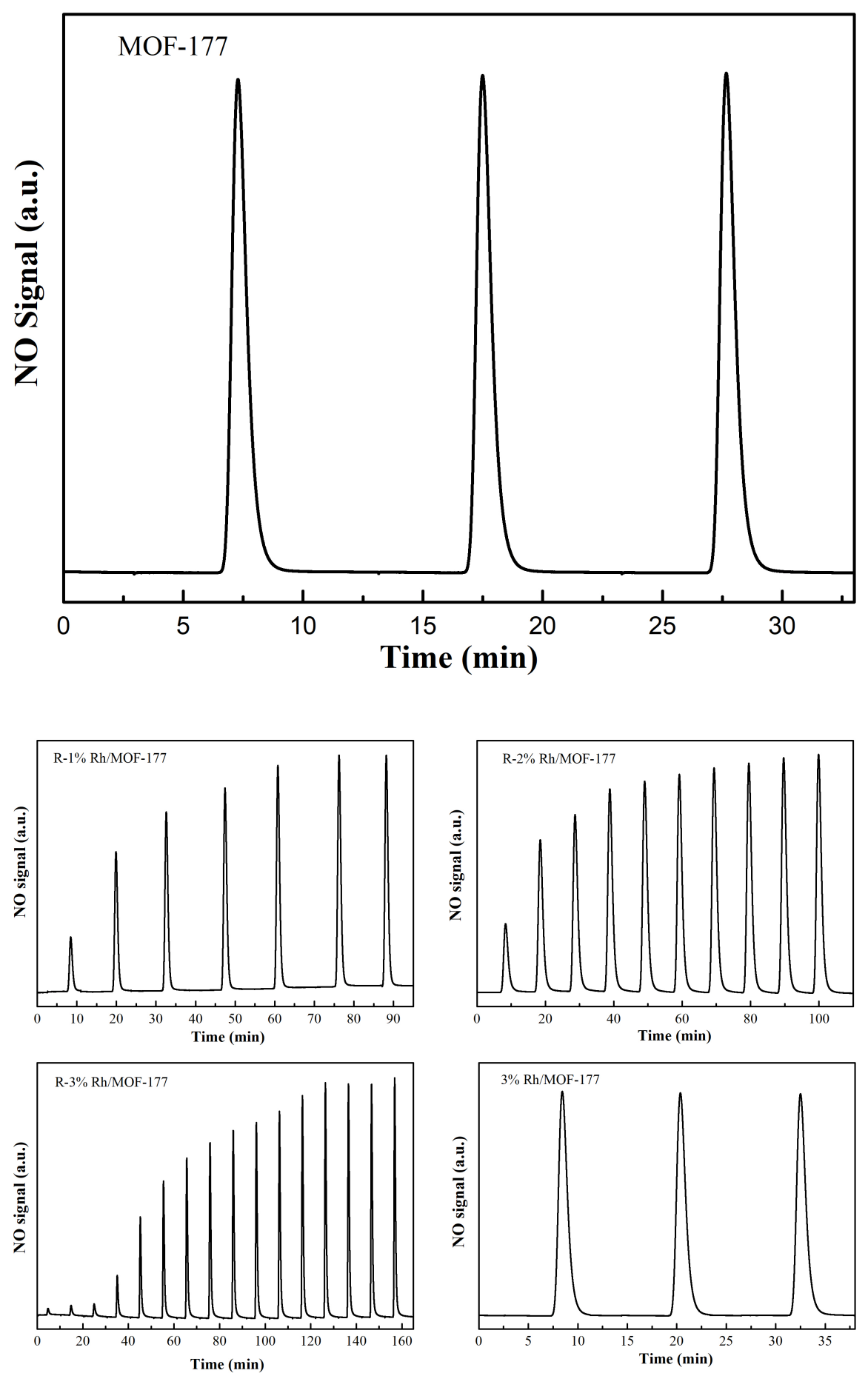

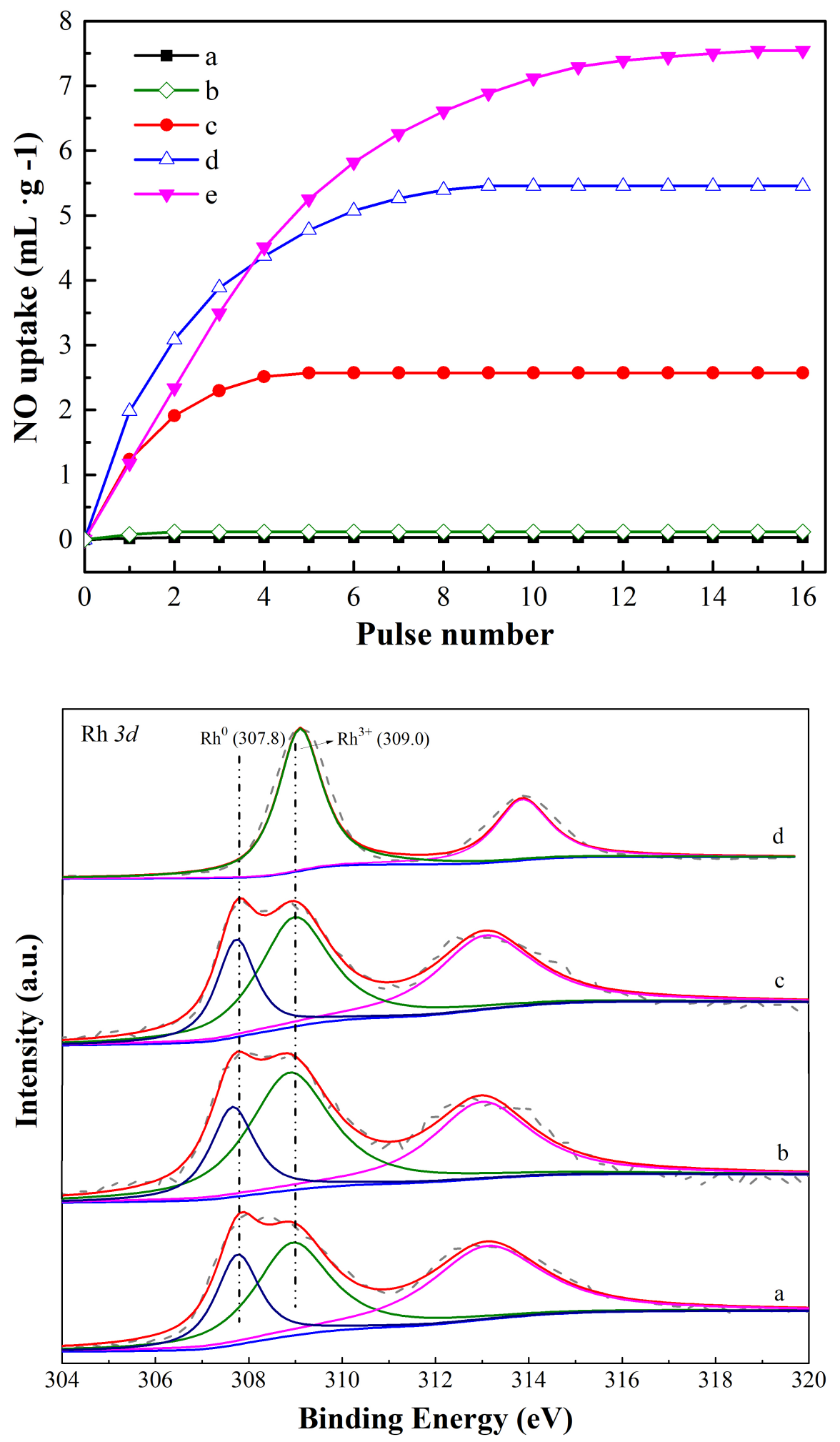


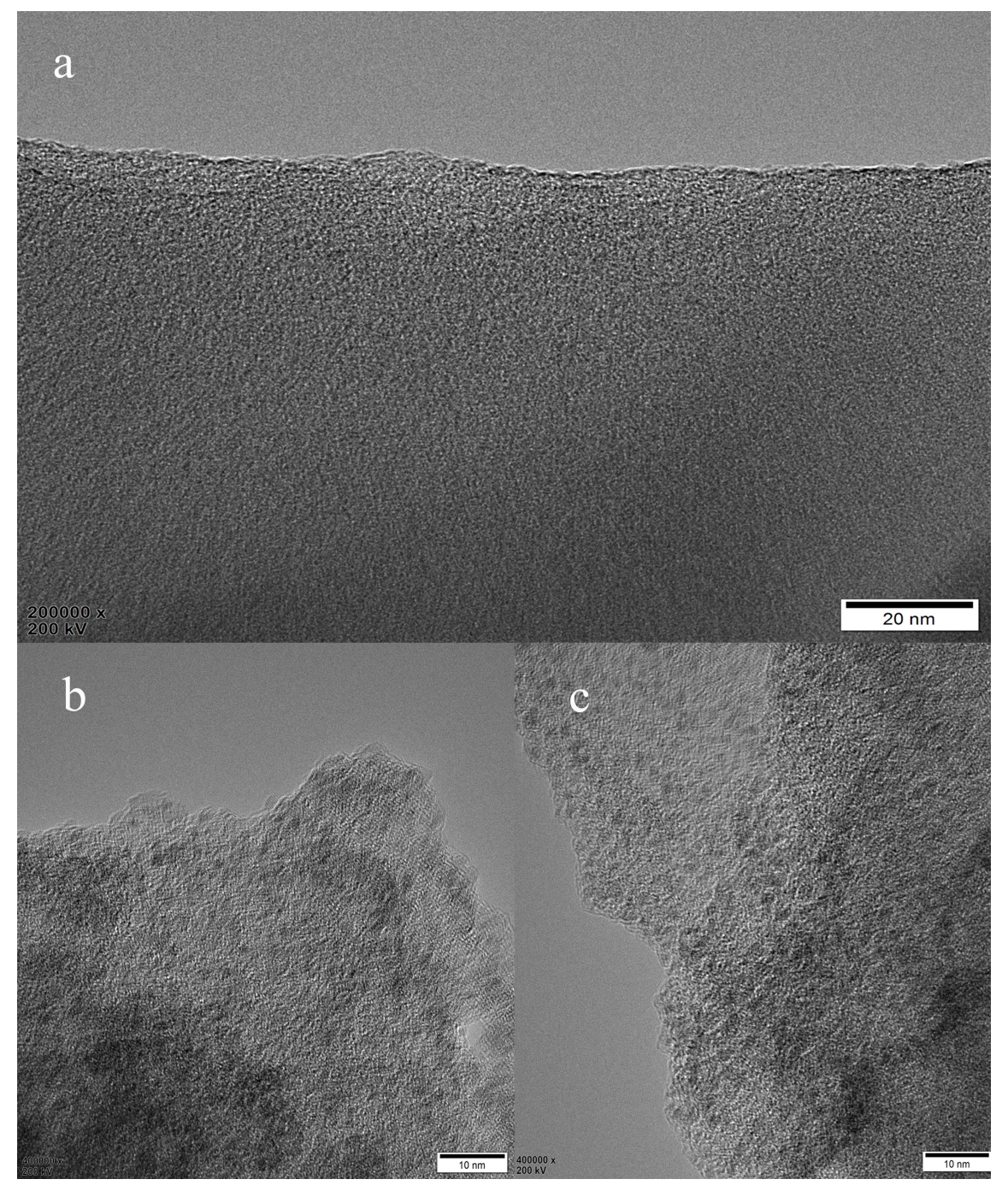




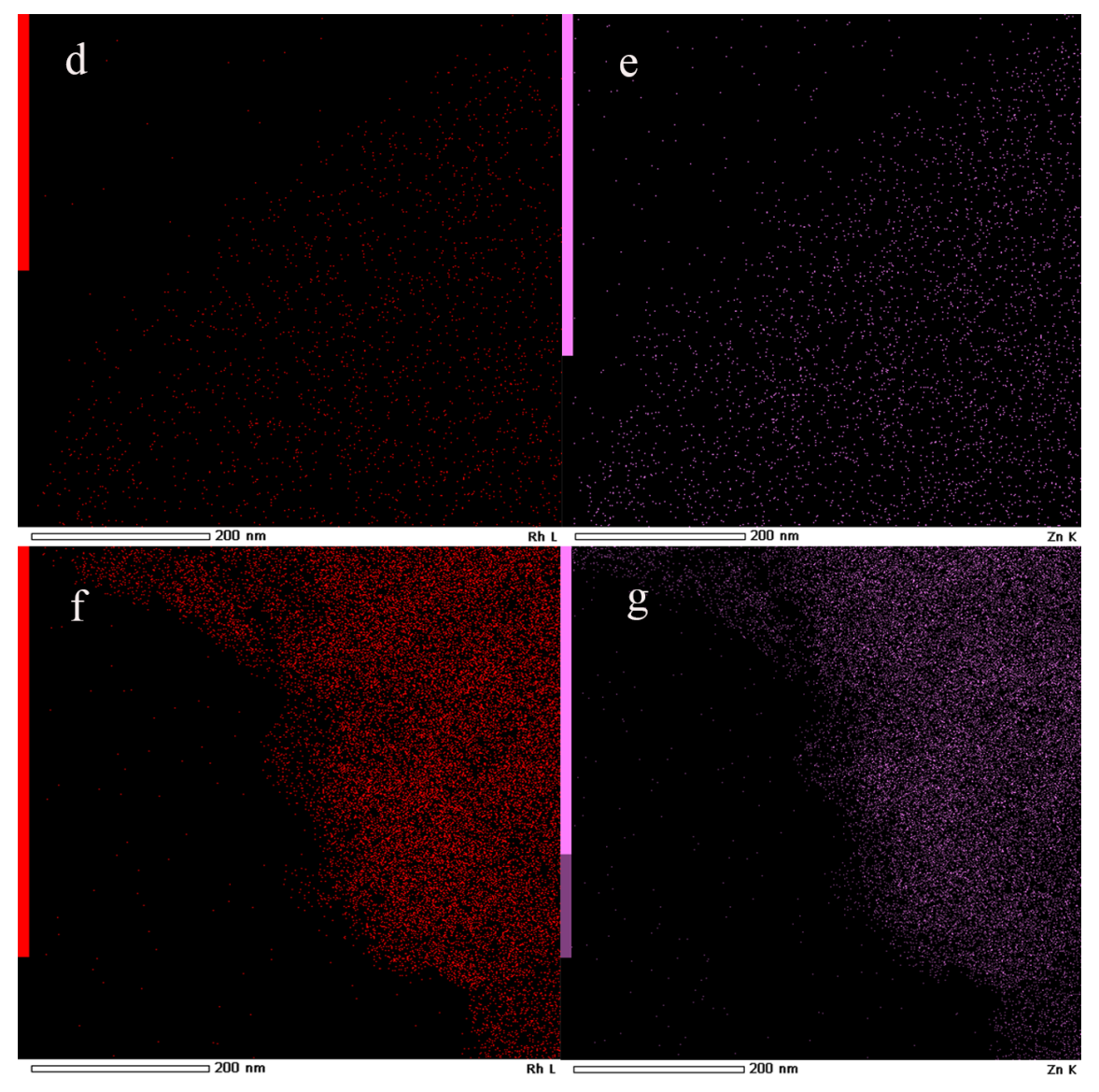



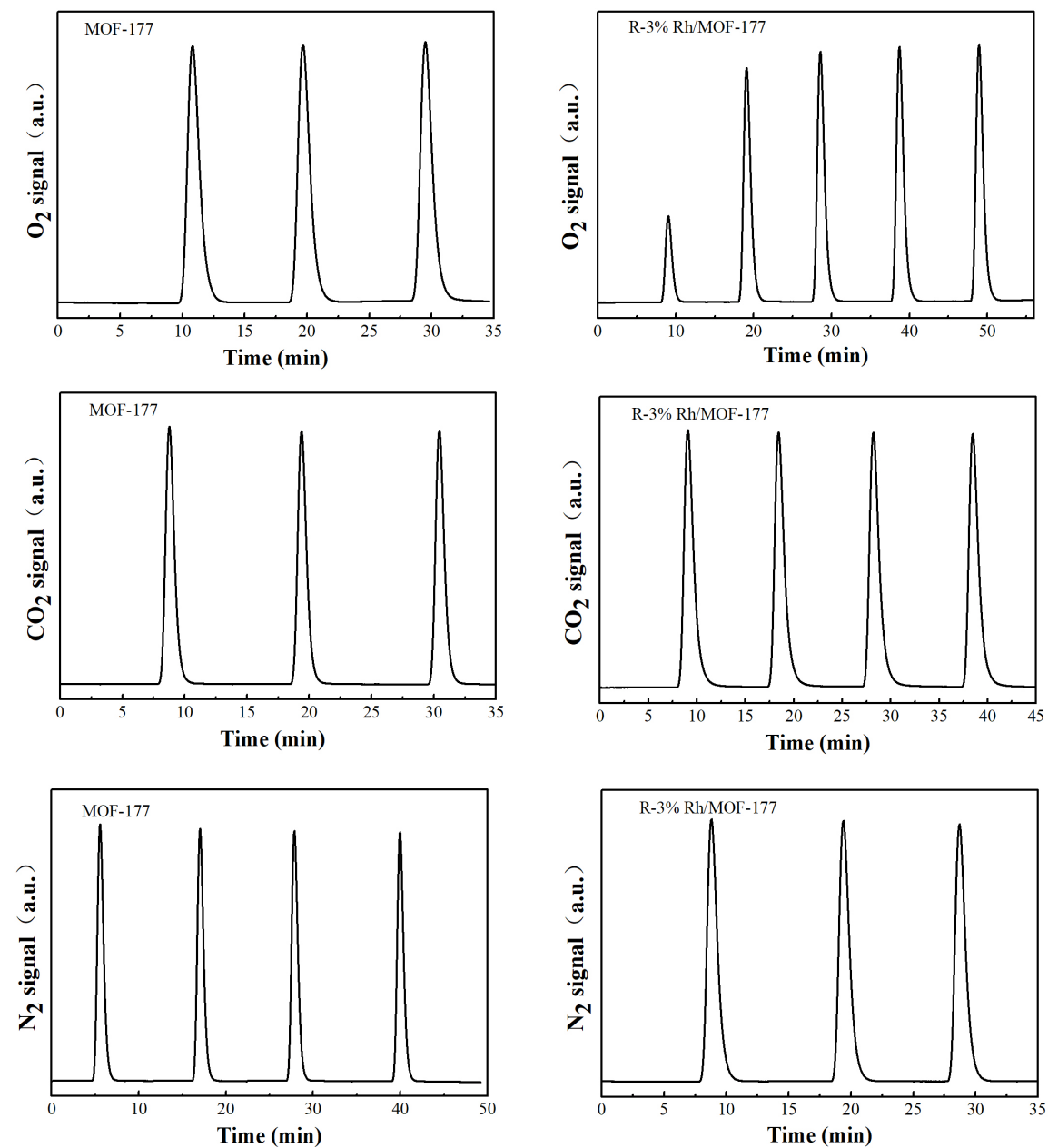

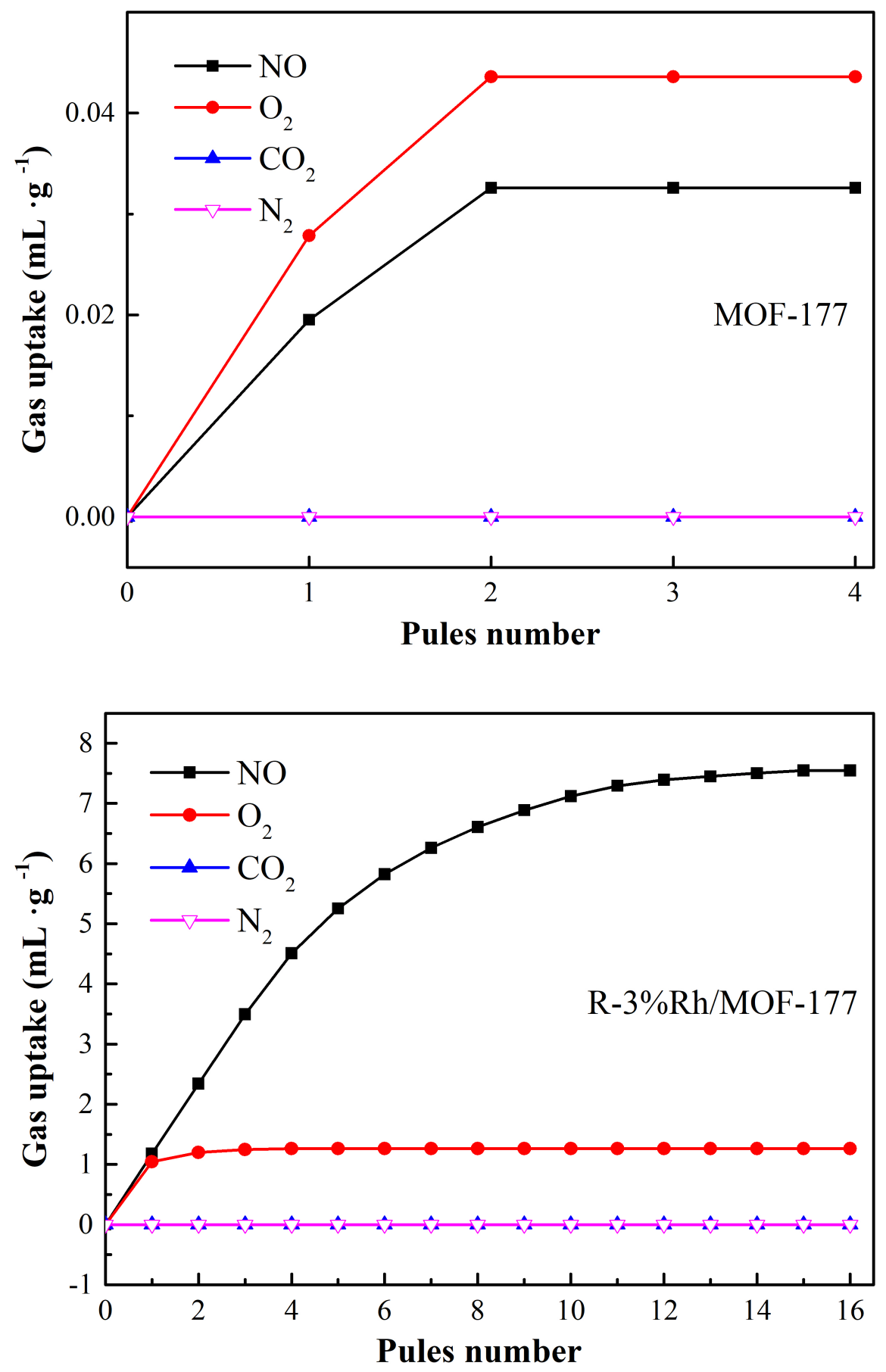

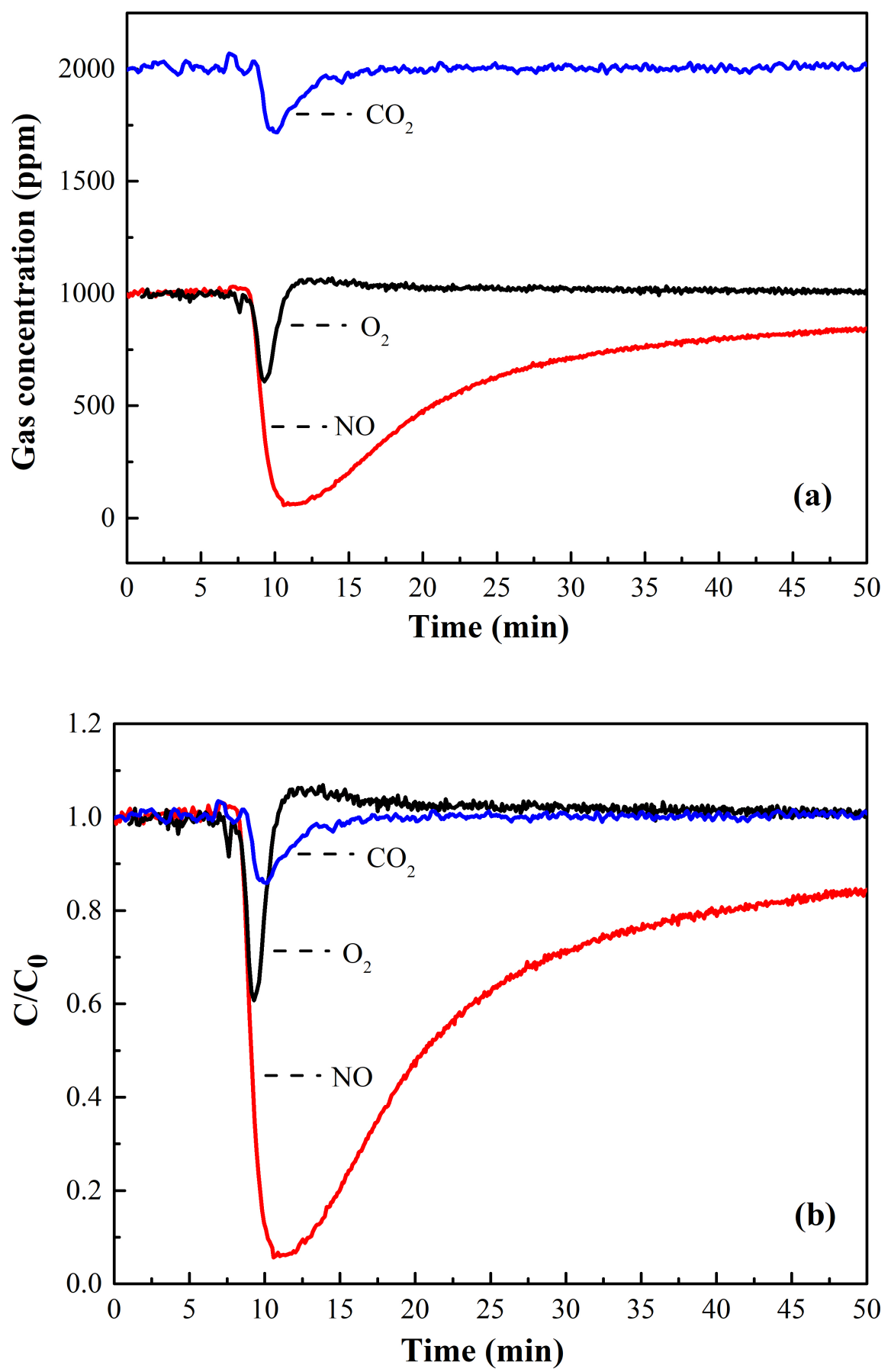


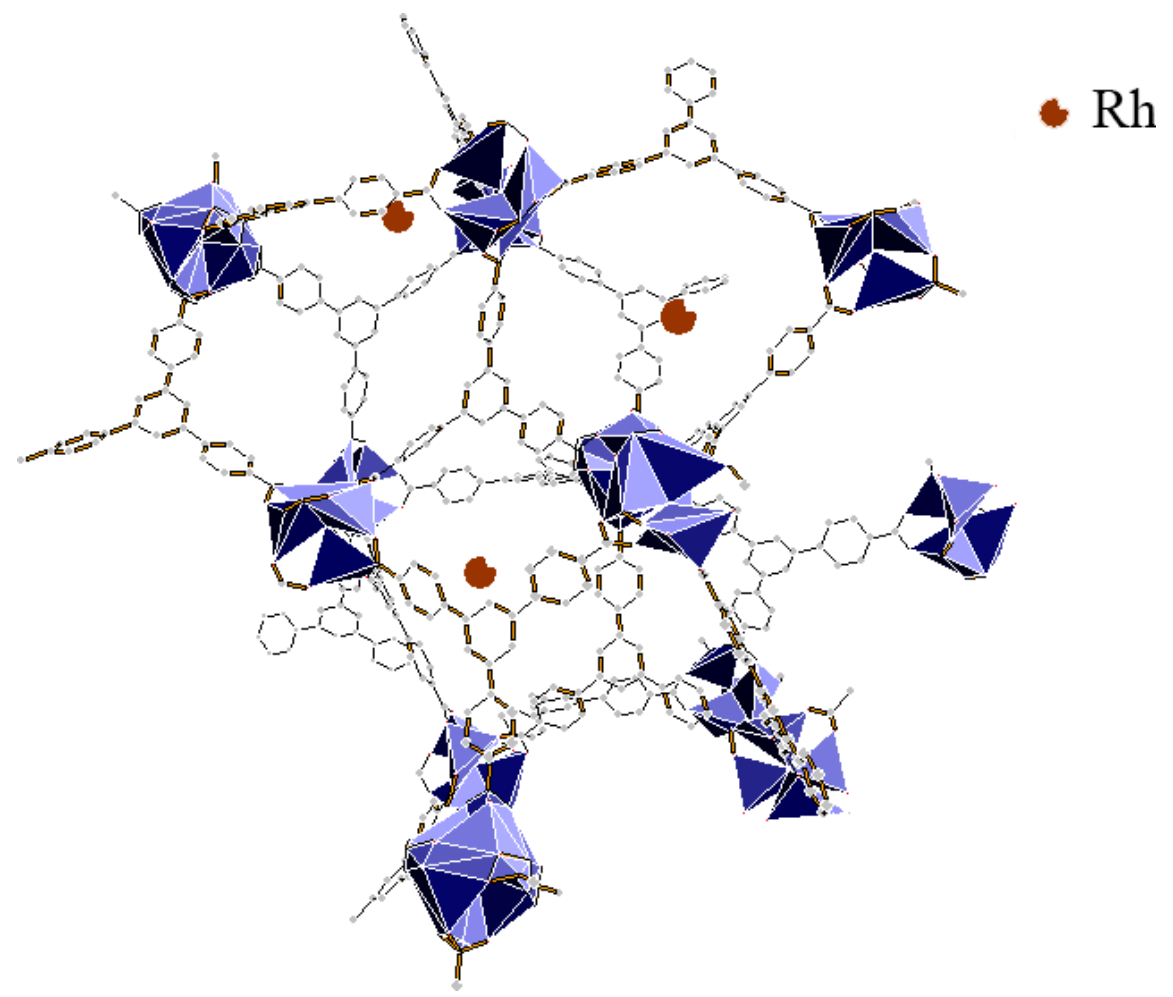

